\title{
A [3+2] Cyclization of Siloxyalkynes and Isocyanides for the Syn- thesis of Oxazoles
}

\author{
An Wu \\ Jianwei Sun* (i) \\ Department of Chemistry, The Hong Kong University of Science and Technology, \\ Clear Water Bay, Kowloon, Hong Kong SAR, P. R. of China \\ sunjw@ust.hk \\ HKUST-Shenzhen Research Institute, No. 9 Yuexing 1st Rd, South Area, Hi-tech \\ Park, Nanshan, Shenzhen 518057, P. R. of China
}

Published as part of the 30 Years SYNLETT - Pearl Anniversary Issue
Received: 29.09.2018

Accepted after revision: 31.10 .2018

Published online: 27.11 .2018

DOI: 10.1055/s-0037-1610402; Art ID: st-2018-w0621-I

License terms: cc)

Abstract A mild and efficient [3+2] cyclization of siloxyalkynes for the synthesis of aromatic heterocycles is developed. It is a new addition to the cyclization reactions of these versatile species. In the presence of TBAF as promoter, siloxyalkynes react with electron-withdrawing isocyanides to form a range of oxazole products. In this reaction, siloxyalkynes contribute the $\mathrm{C}-\mathrm{O}$ unit for the cyclization, which is different from previous typical examples where it is a two-carbon contributor. Mechanistic studies provided insights into the mechanism, which involves a ketene intermediate. Based on the mechanistic insight, an alternative catalytic system was also demonstrated to be effective for the same transformation.

Key words oxazoles, siloxyalkynes, isocyanides, cyclization

Siloxyalkynes, also known as silyl ynol ethers, are a useful type of electron-rich alkynes and a versatile platform for the discovery of new organic reactions. ${ }^{1}$ The presence of the siloxy group attached directly to the alkyne triple bond not only increases its electron density, but also polarizes the triple bond. Consequently, siloxyalkynes can participate in a variety of cyclization reactions with suitable dipolar compounds (Scheme 1). Among these, the most studied cyclizations are [2+2], [4+2], and [6+2] cyclizations to form four-, six-, and eight-membered cyclic compounds. ${ }^{1,2}$ In contrast, there are few reports on the formation of five-membered rings by [3+2] cyclization of siloxyalkynes. ${ }^{3}$ Moreover, siloxyalkynes typically serve as two-carbon units in these cyclization reactions, and have rarely been demonstrated to serve as providers of $\mathrm{C}-\mathrm{O}$ units for cyclization. In continuation of our studies on electron-rich alkynes, ${ }^{2 h-k}$ we report

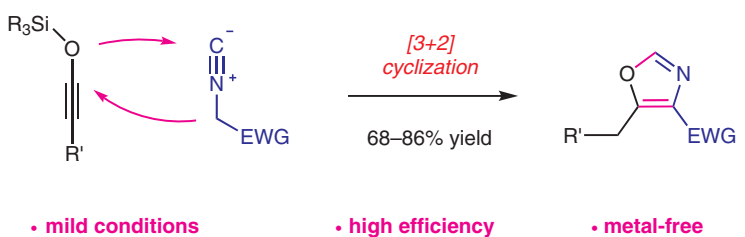

the first [3+2] cyclization of siloxyalkynes for the efficient synthesis of five-membered aromatic heterocycles (1,3-oxazoles), in which siloxyalkynes serve as $\mathrm{C}-\mathrm{O}$ cyclization partners.

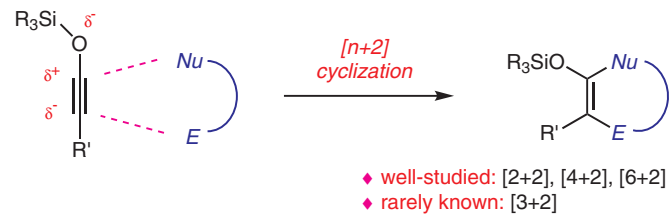

Scheme 1 Siloxyalkynes in cyclization reactions

Oxazoles are an important family of aromatic nitrogencontaining heterocycles, widely present in a range of natural products and bioactive compounds. ${ }^{4}$ In these compounds, the oxazole unit is known to contribute to antifungal, cytotoxic, and anthelmintic activities, among others. Some natural alkaloids even contain multiple oxazole units, thereby indicating the importance of such motifs. For example, marine natural products bengazole $A$ and its homologues, as well as the freshwater natural alkaloid muscoride A, have two oxazole rings in their structures (Figure 1).5,6

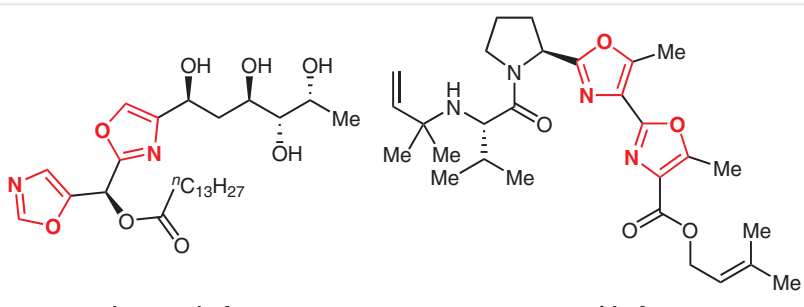

bengazole $A$

muscoride A

Figure 1 Representative oxazole-containing natural alkaloids 
Isocyanides are known synthetic building blocks, widely used for the synthesis of heterocycles. ${ }^{7}$ Specifically, when substituted with an electron-withdrawing group, such compounds can serve as a three-atom unit for cyclization. Therefore, we envisioned that the reaction between a siloxyalkyne and such an isocyanide might proceed in a [3+2] cyclization fashion. Indeed, after considerable efforts to identify suitable conditions, we discovered that the reaction can provide a direct and efficient approach toward the synthesis of oxazoles under metal-free and mild conditions. Notably, in this reaction, siloxyalkynes contribute a C-O unit, rather than a $\mathrm{C}-\mathrm{C}$ unit, for the cyclization (Scheme 2).

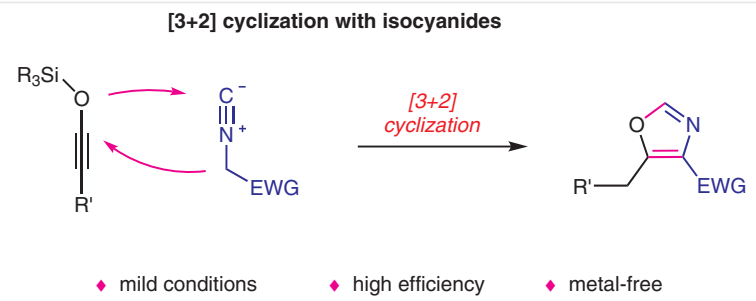

Scheme 2 Synthesis of oxazoles from siloxyalkynes

We began our study with the commercially available isocyanide 4-toluenesulfonylmethyl isocyanide (TosMIC; 1a) and the siloxyalkyne $\mathbf{2 a}$ as model substrates (Table 1 ). After screening of various activators, including Lewis acids and bases, we found that tetrabutylammonium fluoride (TBAF) was the optimum promoter for the desired cyclization (Table 1). The reaction in $\mathrm{CH}_{2} \mathrm{Cl}_{2}$ proceeded in the presence of one equivalent of TBAF to form oxazole $3 a$ in essentially quantitative NMR yield (Table 1 , entry 1 ), and this product was isolated in $83 \%$ yield. In contrast, Lewis acids and Brønsted acids, including In(OTf $)_{3}, \mathrm{AgNTf}_{2}, \mathrm{AgOTf}$, $\mathrm{Sc}(\mathrm{OTf})_{3}, \mathrm{AgSbF}_{6}, \mathrm{HNTf}_{2}, \mathrm{BF}_{3} \cdot \mathrm{OEt}_{2}$, or TMSOTf, failed to promote the same transformation (entry 2). Aiming to further improve the reaction by making it catalytic, we decreased the amount of TBAF and, in fact, the reaction did show catalytic potential. For example, in the presence of $10 \mathrm{~mol} \%$ of TBAF, the product was formed in $72 \%$ yield. However, further improvement by increasing the TBAF loading to substoichiometric levels was not significant. As the commercial TBAF solution (in THF) is typically not anhydrous, we realized that this reaction might not need strict conditions. Thus, the reaction was run without an anhydrous vial or $\mathrm{CH}_{2} \mathrm{Cl}_{2}$. Notably, almost quantitative formation of 3a was still achieved (entry 6). Furthermore, the reaction efficiency was not affected when run in open air (entry 7).

We hypothesized that TBAF might activate the siloxyalkyne by forming a strong Si-F bond. We therefore next screened other fluoride sources. When cesium fluoride or ammonium fluoride was used instead of TBAF, no product was detected at room temperature (Table 1 , entry 8). How-
Table 1 Optimization of the Reaction Conditions ${ }^{\mathrm{a}}$

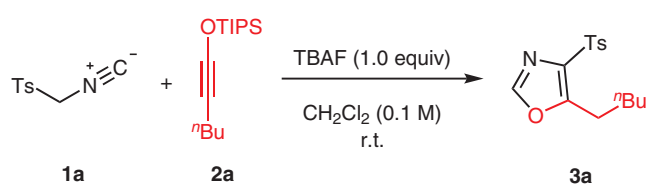

\begin{tabular}{|c|c|c|}
\hline Entry & Variation from the standard conditions & Yield (\%) \\
\hline 1 & none & $99(83)^{c}$ \\
\hline 2 & Lewis or Brønsted acid, instead of TBAF & $0^{d}$ \\
\hline 3 & TBAF (10 mol\%) & 72 \\
\hline 4 & TBAF (20 mol\%) & 76 \\
\hline 5 & TBAF (50 mol\%) & 85 \\
\hline 6 & nondry vial and nonanhyd $\mathrm{CH}_{2} \mathrm{Cl}_{2}$ & 99 \\
\hline 7 & open air, nondry vial, and nonanhyd $\mathrm{CH}_{2} \mathrm{Cl}_{2}$ & 96 \\
\hline 8 & $\mathrm{CsF}$ or $\mathrm{NH}_{4} \mathrm{~F}$ instead of TBAF, r.t. & 0 \\
\hline 9 & CsF instead of TBAF, $60^{\circ} \mathrm{C}$ & 45 \\
\hline 10 & $\mathrm{NH}_{4} \mathrm{~F}$ instead of TBAF, $60^{\circ} \mathrm{C}$ & 0 \\
\hline 11 & CsF instead of TBAF, $\mathrm{H}_{2} \mathrm{O}$ (2.0 equiv), r.t. & 0 \\
\hline 12 & CsF instead of TBAF, $\mathrm{H}_{2} \mathrm{O}$ (2.0 equiv), $60{ }^{\circ} \mathrm{C}$ & 74 \\
\hline
\end{tabular}

ever, heating the reaction mixture to $60{ }^{\circ} \mathrm{C}$ led to the oxazole product in $45 \%$ yield with CsF, but there was still no reaction with $\mathrm{NH}_{4} \mathrm{~F}$ (entries 9 and 10). From a comparison with the reaction in the water-containing TBAF solution, we realized that a small amount of water might be needed. With this in mind, we added two equivalents of water to the above reaction system. Interestingly, the yield was further improved to $74 \%$ with $\mathrm{CsF}$, but not with $\mathrm{NH}_{4} \mathrm{~F}$ (entries 11 and 12). Overall, one equivalent of TBAF was still considered to be optimal for this reaction.

With the standard conditions in hand, we next examined the scope of the reaction. As shown in Scheme 3, a range of siloxyalkynes bearing various substituents reacted with TosMIC (1a) to afford the desired oxazoles $\mathbf{3 a} \mathbf{a}-\mathbf{j}$ with high efficiency. ${ }^{8,9}$ Note that, for the siloxyalkyne bearing a TMS group $(\mathrm{R}=\mathrm{TMS})$, the corresponding product was desilylated under the standard conditions to give 5-methyl-4-tosyloxazole ( $\mathbf{3 h}$ ) as the observed product. In contrast, when a siloxyalkyne containing a TIPS ether motif ( $\mathbf{2 j}$ ) was used, the TIPS group remained intact. Moreover, when the electron-withdrawing group in the isocyanide was changed from a tosyl group to an ester group, the reaction was equally efficient, providing the oxazole $3 \mathbf{k}$ in good yield. Finally, the structure of product $\mathbf{3 i}$ was confirmed by X-ray crystallography (Figure 2). ${ }^{10}$ 


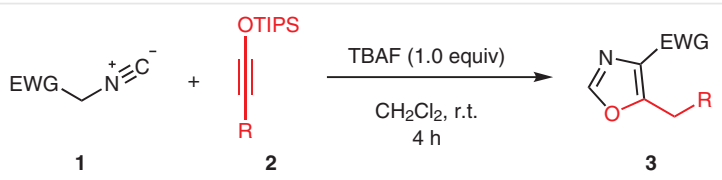<smiles></smiles><smiles>[13CH3]Cc1ocnc1[13OH]</smiles><smiles>[AsH3-]c1ncoc1CC1CC1</smiles>

$3 c, 70 \%$

$$
\text { 3b, } 85 \%
$$

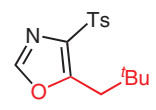

$3 a, 83 \%$<smiles></smiles><smiles>[AsH3-]c1ncoc1CCCc1ccccc1</smiles>

$3 g, 80 \%$

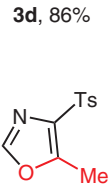

$3 h, 69 \%^{a}$

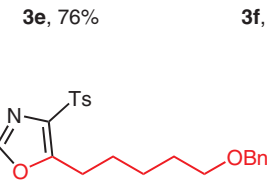

$3 \mathbf{3 i}, 85 \%$

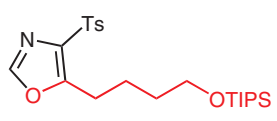

$3 \mathbf{j}, 68 \%$

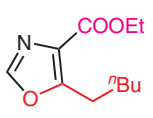

3k, $69 \%$
Scheme 3 Substrate scope. Reaction conditions: $1(0.4 \mathrm{mmol}$ or 0.5 mmol, 1.0 equiv), 2 (1.2 equiv) and TBAF (1.0 equiv, $1.0 \mathrm{M}$ THF solution) in DCM $(0.1 \mathrm{M})$ at r.t. for $4 \mathrm{~h}$. Isolated yields are reported. ${ }^{\mathrm{a}} \mathrm{R}=\mathrm{TMS}$ in substrate.

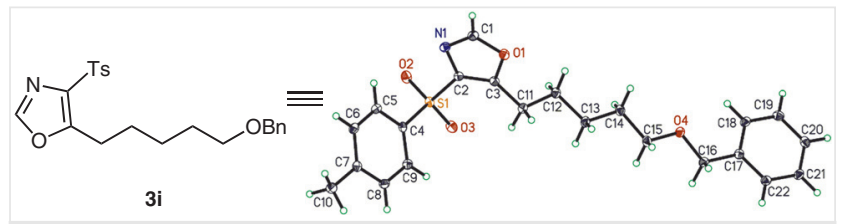

Figure 2 XRD results for compound $\mathbf{3 i}$

The proposed mechanism is shown in Scheme 4. We believe that the fluoride anion in TBAF activates the siloxyalkyne by forming an ynolate ion $\mathbf{A}$, which then deprotonates the isocyanide to form the conjugate base $\mathbf{B}$ and a ketene intermediate $\mathbf{C}$. Subsequent nucleophilic addition to ketene $\mathbf{C}$ by anion $\mathbf{B}$ leads to intermediate $\mathbf{D}$, which cyclizes to give $\mathbf{E}$. A small amount of water present in the reaction mixture then protonates $\mathbf{E}$ to form $\mathbf{F}$. Further aromatization of the ring delivers the observed oxazole product.

During the condition optimization, we noted that TBAF can also be used in a catalytic amount, albeit with a slightly decreased yield. To rationalize this catalytic feature, we reasoned that the hydroxide ion $\left(\mathrm{OH}^{-}\right)$generated from $\mathbf{E}$ to $\mathbf{F}$ might also serve as an active promoter to turn over the reaction. To confirm this possibility, we next evaluated the catalytic ability of the hydroxide ion. In the presence of a catalytic amount of $\mathrm{Bu}_{4} \mathrm{NOH}$, the reaction of $\mathbf{1 a}$ and $\mathbf{2 a}$ proceeded with high efficiency under essentially the same conditions, giving product 3a in $85 \%$ isolated yield [Scheme $5(\mathrm{a})]$. To further probe the generality of this catalytic protocol, we selected and tested other examples under the new conditions. We found that the corresponding oxazoles were

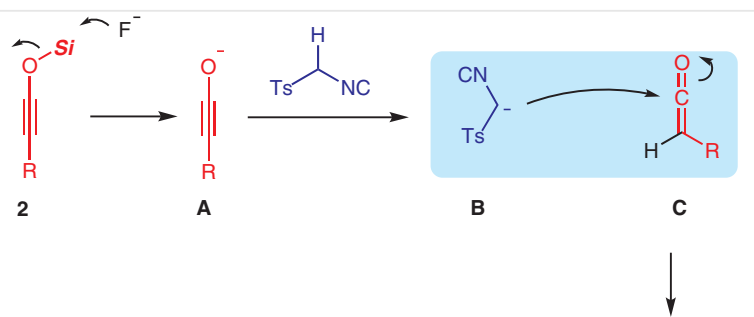

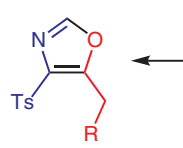

3

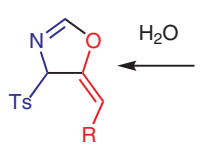

$\mathbf{F}$

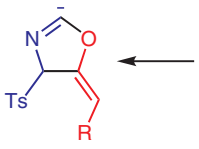

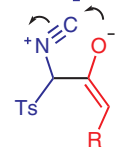

Scheme 4 Proposed mechanism

all obtained with good efficiency, thereby providing an improvement on the original protocol employing a stoichiometric amount of fluoride. Moreover, we also found that isocyanides with a sterically hindered $\alpha$-position did not react efficiently [Scheme 5(b)]. In the absence of an $\alpha$-hydrogen, the reaction did not occur, which is consistent with the proposed mechanism. Furthermore, in the absence of an electron-withdrawing group (e.g., Ts), isocyanide $\mathbf{1 f}$ did not show any reactivity in this reaction, indicating that the $\alpha$-acidity is also critically important. Finally, we also carried out the reaction in the presence of $\mathrm{D}_{2} \mathrm{O}$ with $\mathrm{CsF}$ as the fluoride source [Scheme 5(c)]. In the oxazole product, two positions showed incorporation of deuterium. The presence of deuterium in the oxazole ring is obviously consistent with the mechanism. In addition, the benzylic position was also found to have $27 \%$ incorporation of deuterium. This position is the original acidic position in the isocyanide, which might have pre-exchanged with $\mathrm{D}_{2} \mathrm{O}$ before the reaction. It is also possible that the final aromatization step might be assisted by a water molecule.

In summary, we have developed the first [3+2] cyclization of siloxyalkynes for the synthesis of aromatic heterocycles. In contrast to the previous cyclization reactions of siloxyalkynes where they serve as two-carbon partners, in this reaction the siloxyalkyne contributes a $\mathrm{C}-\mathrm{O}$ unit to the cyclization. In the presence of TBAF as the activator, the reaction between siloxyalkynes and electron-deficient isocyanides proceed efficiently to form a range of substituted oxazoles under mild metal-free conditions. Mechanistic studies indicated that siloxyalkynes serve as the ketene precursor. Inspired by careful analysis, complementary conditions (such as the use of hydroxide as a catalyst) were also identified for this transformation.

\section{Funding Information}

Financial support was provided by the National Science Foundation of China $(21572192,21490570)$ and the Hong Kong RGC (GRF16304714). 
a) Catalytic ability of hydroxide ion

$$
\mathbf{1 a}+\mathbf{2} \underset{\mathrm{CH}_{2} \mathrm{Cl}_{2} \text {, r.t., } 0.5 \mathrm{~h}}{\stackrel{{ }^{n} \mathrm{Bu}_{4} \mathrm{NOH}(10 \mathrm{~mol} \%)}{\longrightarrow}} \mathbf{3}
$$

\begin{tabular}{ccc} 
entry & $\mathbf{3}$ & isolated yield \\
\hline 1 & $\mathbf{3 a}$ & $85 \%$ \\
2 & $\mathbf{3 b}$ & $88 \%$ \\
3 & $\mathbf{3 g}$ & $88 \%$ \\
4 & $\mathbf{3 i}$ & $82 \%$
\end{tabular}

b) Other isocyanides with hindered $\alpha$-position or no $\alpha$-hydrogen
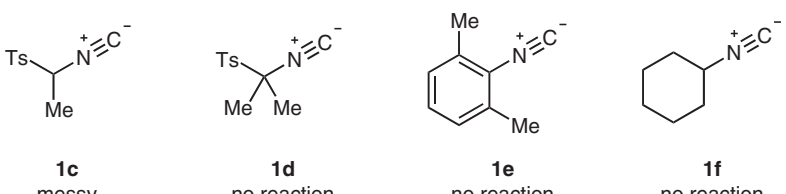

messy

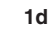

no reaction

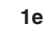

no reaction

$1 f$

(...

c) Outcome with $\mathrm{D}_{2} \mathrm{O}$

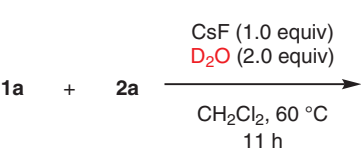

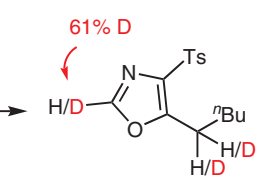

4
Scheme 5 Mechanistic studies

\section{Supporting Information}

Supporting information for this article is available online at https://doi.org/10.1055/s-0037-1610402.

\section{References and Notes}

(1) For reviews on siloxyalkynes, see: (a) Qian, H.; Zhao, W.; Sun, J. Chem. Rec. 2014, 14, 1070. (b) Shindo, M. Synthesis 2003, 2275. (c) Shindo, M. Tetrahedron 2007, 63, 10.

(2) For selected examples of cyclization reactions of siloxyalkynes, see: (a) Sweis, R. F.; Schramm, M. P.; Kozmin, S. A. J. Am. Chem. Soc. 2004, 126, 7442. (b) Danheiser, R. L.; Gee, S. K. J. Org. Chem. 1984, 49, 1672. (c) Danheiser, R. L.; Gee, S. K.; Perez, J. J. J. Am. Chem. Soc. 1986, 108, 806. (d) Movassaghi, M.; Hill, M. D.; Ahmad, O. K. J. Am. Chem. Soc. 2007, 129, 10096. (e) Türkmen, Y. E.; Montavon, T. J.; Kozmin, S. A.; Rawal, V. H. J. Am. Chem. Soc. 2012, 134, 9062. (f) Montavon, T. J.; Türkmen, Y. E.; Shamsi, N. A.; Miller, C.; Sumaria, C. S.; Rawal, V. H.; Kozmin, S. A. Angew. Chem. Int. Ed. 2013, 52, 13576. (g) Cabrera-Pardo, J. R.; Chai, D. I.; Liu, S.; Mrksich, M.; Kozmin, S. A. Nat. Chem. 2013, 5, 423. (h) Zhao, W.; Wang, Z.; Sun, J. Angew. Chem. Int. Ed. 2012, 51, 6209. (i) Zhao, W.; Li, Z.; Sun, J. J. Am. Chem. Soc. 2013, 135, 4680. (j) Zhao, W.; Sun, J. Synlett 2014, 25, 303. (k) Zhao, W.; Qian, H.; Li, Z.; Sun, J. Angew. Chem. Int. Ed. 2015, 54, 10005.
(3) We are aware of only two examples, see: (a) Qi, X.; Ready, J. M. Angew. Chem. 2008, 120, 7176. (b) Buchner, K. M.; Woerpel, K. A. Organometallics 2010, 29, 1661.

(4) Yeh, V. S. C. Tetrahedron 2004, 60, 11995.

(5) (a) Adamczeski, M.; Quiñoá, E.; Crews, P.J. Am. Chem. Soc. 1989, 111, 647. (b) Searle, P. A.; Richter, R. K.; Molinski, T. F. J. Org. Chem. 1996, 61, 4073.

(6) Nagatsu, A.; Kajitani, H.; Sakakibara, J. Tetrahedron Lett. 1995, 36, 4097.

(7) For reviews on isocyanides, see: (a) Boyarskiy, V. P.; Bokach, N. A.; Luzyanin, K. V.; Kukushkin, V. Yu. Chem. Rev. 2015, 115, 2698. (b) Van Leusen, D.; Van Leusen, A. M. Org. React. (N. Y.) 2001, 57, 417.

(8) For other examples of oxazole synthesis, including the use of isocyanides, see: (a) Robinson, R. J. Chem. Soc., Trans. 1909, 95, 2167. (b) Gabriel, S. Ber. Dtsch. Chem. Ges. 1910, 43, 134. (c) Wiley, R. H. Chem. Rev. 1945, 37, 401. (d) Nunami, K.-I.; Suzuki, M.; Yoneda, N. J. Org. Chem. 1979, 44, 1887. (e) van de Coevering, R.; Kuil, M.; Gebbink, R. J. M. K.; van Koten, G. Chem. Commun. 2002, 1636. (f) Sladojevich, F.; Trabocchi, A.; Guarna, A.; Dixon, D. J. J. Am. Chem. Soc. 2011, 133, 1710. (g) Franchino, A.; Jakubec, P.; Dixon, D. J. Org. Biomol. Chem. 2016, 14, 93. (h) Zhang, M.-Z.; Jia, C.-Y.; Gu, Y.-C.; Mulholland, N.; Turner, S.; Beattie, D.; Zhang, W.-H.; Yang, G.-F.; Clough, J. Eur. J. Med. Chem. 2017, 126, 669. (i) Suzuki, M.; Iwasaki, T.; Miyoshi, M.; Okumura, K.; Matsumoto, K. J. Org. Chem. 1973, 38, 3571. (j) Huang, W.-S.; Zhang, Y.-X.; Yuan, C.-Y. Synth. Commun. 1996, 26, 1149. (k) Baumann, M.; Baxendale, I. R.; Ley, S. V.; Smith, C. D.; Tranmer, G. K. Org. Lett. 2006, 8, 5231. (l) El Kaim, L.; Grimaud, L.; Schiltz, A. Tetrahedron Lett. 2009, 50, 5235. (m) Dos Santos, A.; El Kaim, L.; Grimaud, L.; Ronsseray, C. Chem. Commun. 2009, 3907. (n) Ma, Y.; Yan, Z.; Bian, C.; Li, K.; Zhang, X.; Wang, M.; Gao, X.; Zhang, H.; Lei, A. Chem. Commun. 2015, 51, 10524. (o) Liao, J.-Y.; Ni, Q.; Zhao, Y. Org. Lett. 2017, 19, 4074. (p) Pan, J.; Li, X.; Lin, F.; Liu, J.; Jiao, N. Chem 2018, 4, 1427.

(9) 5-Pentyl-4-tosyl-1,3-oxazole (3a); Typical Procedure $\mathrm{CH}_{2} \mathrm{Cl}_{2}(4 \mathrm{~mL})$ was added to a $10 \mathrm{~mL}$ vial charged with isocyanide $\mathbf{1 a}\left(0.4 \mathrm{mmol}, 1.0\right.$ equiv) at r.t. under $\mathrm{N}_{2}$. Siloxyalkyne 2a $(0.48 \mathrm{mmol}, 1.2$ equiv) and a $1.0 \mathrm{M}$ solution of TBAF in THF $(0.4$ mmol, 1.0 equiv) were added sequentially, and the mixture was stirred at r.t. for 4 h. Next, $\mathrm{H}_{2} \mathrm{O}(5 \mathrm{~mL})$ was added, and the layers were separated. The aqueous layer was extracted with $\mathrm{CH}_{2} \mathrm{Cl}_{2}$ (3 $\times 5 \mathrm{~mL}$ ). The combined organic layers were dried $\left(\mathrm{Na}_{2} \mathrm{SO}_{4}\right)$, filtered, and concentrated. The residue was purified by chromatography [silica gel, hexanes-EtOAc (10:1)] to give a pale-yellow semisolid; yield: $97.9 \mathrm{mg}$ (83\%). IR (neat): 3134, 3057, 2932, $2865,1589,1516,1455,1325,1145,1084 \mathrm{~cm}^{-1} .{ }^{1} \mathrm{H}$ NMR $(400$ $\left.\mathrm{MHz}, \mathrm{CDCl}_{3}\right): \delta=7.89(\mathrm{~d}, J=8.3 \mathrm{~Hz}, 2 \mathrm{H}), 7.71(\mathrm{~s}, 1 \mathrm{H}), 7.32(\mathrm{~d}, J=$ $8.0 \mathrm{~Hz}, 2 \mathrm{H}), 3.08(\mathrm{t}, J=7.6 \mathrm{~Hz}, 2 \mathrm{H}), 2.40(\mathrm{~s}, 3 \mathrm{H}), 1.75-1.62(\mathrm{~m}, 2$ $\mathrm{H}), 1.38-1.26(\mathrm{~m}, 4 \mathrm{H}), 0.92-0.83(\mathrm{~m}, 3 \mathrm{H}) .{ }^{13} \mathrm{C}$ NMR $(101 \mathrm{MHz}$, $\left.\mathrm{CDCl}_{3}\right): \delta=157.2,149.4,144.7,137.3,135.1,129.7,127.9,31.0$, $27.5,25.2,22.1,21.5,13.8$. HRMS (CI): $m / z[\mathrm{M}+\mathrm{H}]^{+}$calcd for $\mathrm{C}_{15} \mathrm{H}_{20} \mathrm{NO}_{3} \mathrm{~S}$ : 294.1164; found: 294.1158.

(10) CCDC 1869561 contains the supplementary crystallographic data for compound $3 \mathbf{i}$. The data can be obtained free of charge from The Cambridge Crystallographic Data Centre via www.ccdc.cam.ac.uk/getstructures. 